\title{
Mesenchymal stem cell therapies for liver cirrhosis: MSCs as "conducting cells" for improvement of liver fibrosis and regeneration
}

\author{
Atsunori Tsuchiya*, Suguru Takeuchi, Takayuki Watanabe, Tomoaki Yoshida, Shunsuke Nojiri, Masahiro Ogawa and \\ Shuji Terai*
}

\begin{abstract}
Mesenchymal stem cells (MSCs) can be cultured relatively easily and can be obtained not only from the bone marrow, but also from medical waste such as adipose tissue and umbilical cord tissue. Because of its low antigenicity, allogeneic MSC injection is safe. MSCs have been evaluated in more than 900 clinical trials in a variety of fields, with more than 50 clinical trials related to liver diseases. Experiments have suggested that MSCs function as "conducting cells" to affect various "effective cells" such as T cells, B cells, and macrophages. Recent clinical trials have focused on allogeneic MSCs. Thus, studies are needed to determine the most effective cell source, culture conditions, cell numbers, administration frequency, administration route, cost, safety, and liver disease treatments. Recently, the functions of exosomes have gained attention, and cell-free therapy may become possible as an alternative therapy for liver disease. In this review, we introduce general information, mechanism, representative clinical study data, recently started or planned clinical trials, and possibility of cell-free therapy of MSCs.
\end{abstract}

Keywords: Liver cirrhosis, Acute on chronic, Mesenchymal stem cell, Cell therapy

\section{Background}

The liver, which is a vital organ, has many functions such as protein, triglyceride, cholesterol, and glycogen synthesis; detoxication; drug metabolism; and bile secretion, and has a high regenerative potential. However, the liver cannot withstand long-term chronic injury, severe acute injury, and acute on chronic injury. Chronic liver injuries such as those caused by hepatitis B virus (HBV) and hepatitis $C$ virus infections, non-alcoholic steatohepatitis (NASH), and alcoholic liver injury have been widely studied. Because of the recent development of anti-viral drugs, it is easy to control HBV [1] and eradicate hepatitis $\mathrm{C}$ virus [2]. In contrast, the number of patients with $\mathrm{NASH}$ and alcoholic liver disease is increasing and no effective drugs except conventional alimentary therapy and exercise therapy are available;

\footnotetext{
*Correspondence: atsunori@med.niigata-u.ac.jp; terais@med.niigata-u.ac.jp Division of Gastroenterology and Hepatology, Graduate School of Medical and Dental Science, Niigata University, 1-757 Asahimachi-dori, Chuo-ku, Niigata 951-8510, Japan
}

thus, development of new therapies for these diseases is becoming important [3]. Long-term damaged conditions gradually result in the loss of liver function and accumulation of extracellular matrix (ECM), finally leading to liver cirrhosis. Particularly, the prognosis of patients with decompensated liver cirrhosis is poor. Hepatic stellate cells are central players in liver fibrosis and the major precursors of activated myofibroblasts, which produce ECM during liver fibrosis $[4,5]$. A recent study reported that fibrosis, rather than steatosis, determines the prognosis of patients [6,7]. In acute liver injury such as hepatitis B, hepatitis A, and drug-induced liver injury, patients with excessive damage cannot be sufficiently treated by physicians. Additionally, acute on chronic liver failure (ACLF), the definition of which slightly differs by region [8-11], is also a recently focused disease condition. Recently proposed diagnostic criteria for ACLF in Japan include "patients with cirrhosis and a Child-Pugh score of 5-9 should be diagnosed as having ACLF when a deterioration of liver function (serum bilirubin level $\geq 5.0 \mathrm{mg} / \mathrm{dL}$ and prothrombin time value $\leq 40 \%$ of the standardized values and/or 
international normalization rate $\geq 1.5$ ) caused by severe liver damage develops within 28 days after acute insults, such as alcohol abuse, bacterial infection, gastrointestinal bleeding, or the exacerbation of underlying liver diseases" [11]. These chronic, acute, and acute on chronic liver injuries can cause death. Although liver transplantation can be conducted, the shortage of donor organs is a serious problem. Cell therapies may be useful for treating these diseases. We firstly showed that autologous bone marrow cell infusion (ABMi) therapy was effective for the decompensation of liver cirrhosis patients [12]. Several clinical cases in this study [13] have shown that bone marrow-derived cells can improve liver fibrosis and subsequently improve liver function. Therefore, recently, we shifted our focus to cell therapies using mesenchymal stem cells. Mesenchymal stem cells (MSCs) have been widely examined in clinical trials to evaluate their safety and effectiveness in improving liver fibrosis and liver function. Positive results have been observed in numerous studies of animal models [14-17].

In this review, we describe the general information of MSCs, mechanisms of MSC therapies (i.e., the conducting effect of MSCs), recently published outcomes of MSC therapy, clinical trials that have recently started or will begin soon, and recent research trends using extracellular vesicles obtained from MSCs.

\section{General information of MSCs}

MSCs have been used in many fields to treat a variety of diseases such as neural, heart, liver, intestinal, and lung diseases. According to ClinicalTrials.Gov, more than 900 clinical trials have been registered in a variety of fields and are increasing by nearly 100 trials each year. MSCs can be obtained not only from the bone marrow, but also from medical waste such as umbilical cord tissue, adipose tissue, amniotic tissue, and dental pulp. These cells are relatively easy to expand, maintain, and cryopreserve, while maintaining their viability. MSCs are positive for the common markers CD73, CD90, and CD105 and show differential potential towards adipocytes, osteoblasts, and chondroblasts under appropriate conditions. The cells are used to replace damaged cells or tissues mainly in the orthopedic field; however, their main functions are determined by trophic factors including chemokines, cytokines, growth factors, and exosomes, and MSCs exhibit anti-inflammation, anti-oxidant, angiogenesis, and anti-fibrosis effects $[4,5]$. Of these functions, MSCs are most commonly applied to achieve anti-inflammation effects. MSCs produce various factors such as nitric oxide/indoleamine 2,3-dioxygenase, interleukin (IL)-10, tumor necrosis factor-inducible gene-6, and prostaglandin E2; inhibit T cell activation and expansion; induce regulatory $\mathrm{T}$ cells; alter the polarity of macrophages to the anti-inflammatory phenotype; and control the function of dendritic cells, B cells, and natural killer cells $[18,19]$. Another important characteristic of MSCs is that they generally have low immunogenicity. MSCs express low or modest levels of major histocompatibility complex class I molecules and lack expression of major histocompatibility complex class II and co-stimulatory molecules, such as CD40, CD80, and CD86 (B7-2), leading to low immunogenicity, suggesting that MSCs can avoid immune responses in recipients; thus, injection of autologous or allogenic MSCs has been employed in clinical studies. For example, Lalu et al. performed a meta-analysis of the safety of MSCs in clinical trials and found that autologous and allogenic MSC therapies are related to transient fever but not related to infusion toxicity, organ system complications, infection, death, and malignancies [20]. Allogenic MSC therapy has the potential to be applied in many patients.

\section{MSCs function as "conducting cells" in liver disease}

The mechanisms of MSCs for treating liver diseases have been evaluated from various perspectives in basic studies. MSCs have anti-inflammatory effects and reduce damages to hepatocytes [21]. These anti-inflammatory effects and decreases in hepatocyte damage reduce the activation of hepatic stellate cells [22] and direct the effects of MSCs to reduce hepatic stellate cell activation [23]. Additionally, we recently reported the effects against macrophages. MSCs change the polarity of macrophages towards an anti-inflammatory phenotype, increase the production of matrix metalloproteinases to reduce the ECM, and increase the ability of phagocytosis of hepatocyte debris (during this process, macrophages increase the levels of pro-regenerative factors) (Fig. 1) [14]. When we administered bone marrow-derived MSCs with macrophages produced by culturing bone marrow cells for 7 days, host macrophages and neutrophils were also recruited to the liver.

The behaviors of macrophages after administration showed differences between studies. Some studies reported that administered MSCs can migrate to and function in the liver [24]. However, our recent studies of a liver cirrhosis mouse model using two-photon excitation microscopy revealed that when bone marrow-derived macrophages (green fluorescent protein-labeled) and MSCs (DsRed-labeled) were administered at the same time via the tail vein, most MSCs migrated to the lung and a low percentage of MSCs migrated to the liver, which disappeared from both the lung and liver after 7 days. In contrast, macrophages migrated to both the lung and liver, where they remained for 7 days. Particularly, in the liver, administered macrophages migrated to the damaged area where excess ECM and hepatocyte debris were detected. Furthermore, we observed that the administered GFP-positive macrophages phagocytosed the debris in hepatocytes in the liver [14]. 


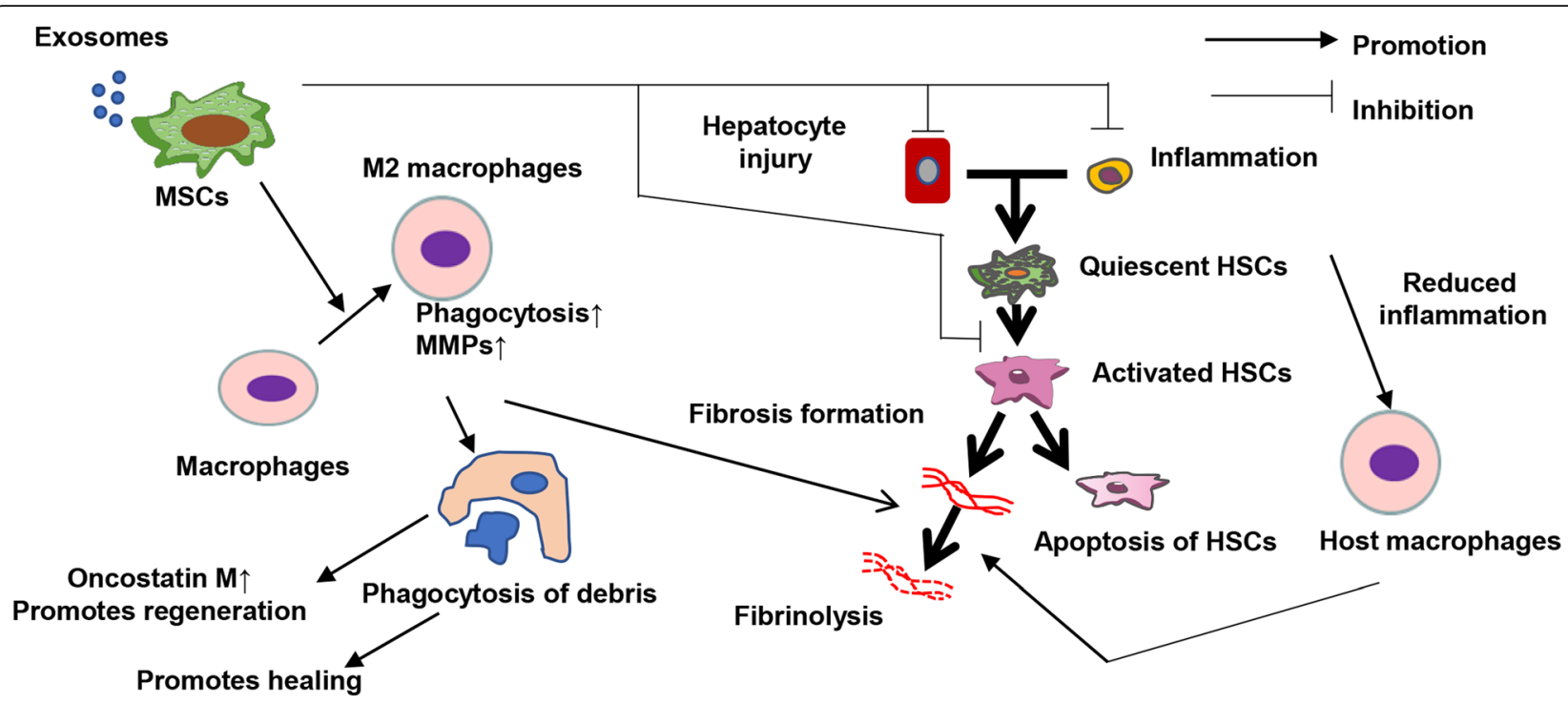

Fig. 1 Mechanisms of MSCs for liver disease. MSCs have various effects including the reduction of hepatocyte injury and inflammation. Additionally, MSCs affect macrophages and increase matrix metalloproteinase expression and phagocytosis, promoting the regenerative process

While some aspects of the mechanisms of MSCs remain unclear, these results revealed that MSCs function indirectly as "conducting cells," while macrophages, T cells, B cells, and other cells function directly as "effective cells."

\section{Summary of MSC therapies from recently published papers}

Many reports have been published describing the results of clinical trials using MSCs. Zhao et al. reported a meta-analysis of previously published papers up to June 2017. They evaluated 23 reports of studies comparing MSC therapy to conventional treatment. The authors concluded that MSCbased therapy is relatively safe and improved liver function during the first 6 months after administration. A single injection administration via the hepatic artery and MSCs derived from the bone marrow are optimal in terms of improving liver function [25]. The analyzed cases were quite heterogenous and included papers only written in Chinese; thus, next, we show two representative studies.

Suk et al. reported a phase II study using bone marrow-derived MSCs for treating alcoholic liver cirrhosis. An MSC culture from 10 to $20 \mathrm{ml}$ of bone marrow aspirated 1 month before the first injection was administered one or two times $\left(5 \times 10^{7}\right.$ cells/time $)$ via the hepatic artery and compared to the control. Results of biopsy performed 6 months after cell administration revealed 25\% (one-time cell administration) and 37\% (two administrations) reductions in the fibrosis area. Furthermore, the Child-Pugh scores of both the single and double administration groups were improved significantly at 12 months after cell injection [26].

Lin et al. reported an open-label non-blinded randomized controlled study using $1.0-10 \times 10^{5}$ cells $/ \mathrm{kg}$ of allogeneic bone marrow cells for treating patients with
HBV-related ACLF once per week for 4 weeks; these subjects were followed for 24 weeks. The clinical laboratory results showed that serum total bilirubin and model for end-stage liver disease scores were improved compared to those obtained after standard medical therapy. The authors further observed that the incidences of severe infection and mortality from multiple organ failure were reduced after cell administration [27].

Two representative cases of cirrhosis and ACLF of MSC therapy were shown above, both of which were treated safely and showed some favorable effects. Based on these studies, additional clinical studies were designed. The next section describes recently designed clinical trials.

\section{Recently started or planned clinical trials}

To describe recent trends in clinical trials using MSCs, we evaluated clinical studies which began or will begin after 1 January 2017 according to ClinicalTrials.gov. Thirteen clinical trials were registered; 1 case was a follow-up study of a clinical trial, and thus, we excluded this case and analyzed the other 12 cases. As shown in Tables 1,8 of 12 (66.7\%) cases were from China and 1 case (8.3\%) each occurred in Germany, Japan, Taiwan, and Singapore (Fig. 2a). Four of 12 cases (33.3\%) were ACLF, 7 of 12 cases (58.3\%) were cirrhosis in which each study's etiology of cirrhosis slightly differed, and 1 case $(8.3 \%)$ was a target for primary biliary cholangitis (Fig. 2b). Five of $12(41.6 \%)$ cases were treated with allogeneic MSCs, and 2 of 12 cases were treated with autologous MSCs (16.7\%). In 5 of 12 cases, it was unclear whether allogeneic or autologous cells were used; however, based on the study design and disease condition, allogeneic MSCs were administered in most cases, suggesting that allogeneic cases were increased compared to previously 
Table 1 Recently started or planned clinical trials

\begin{tabular}{|c|c|c|c|c|c|c|c|c|c|}
\hline & Country & Conditions & $\begin{array}{l}\text { Auto/ } \\
\text { Allo }\end{array}$ & Origin & Cell number & $\begin{array}{l}\text { Cell injection } \\
\text { times }\end{array}$ & Route & Phase & Study design \\
\hline 1 & China & ACLF & N/A & $\mathrm{N} / \mathrm{A}$ & $1-10 \times 10^{5} / \mathrm{kg}$ & 4 & $\begin{array}{l}\text { Peripheral } \\
\text { vein }\end{array}$ & $|/| \mid$ & Randomized/open label \\
\hline 2 & China & ACLF & N/A & N/A & $0.1-1 \times 10^{6} / \mathrm{kg}$ & 3 & $\begin{array}{l}\text { Peripheral } \\
\text { vein }\end{array}$ & N/A & $\begin{array}{l}\text { Randomized/double } \\
\text { blind }\end{array}$ \\
\hline 3 & Germany & ACLF & Allo & $\begin{array}{l}\text { Skin (ABCB5+ } \\
\text { cells) }\end{array}$ & $2 \times 10^{6} / \mathrm{kg}$ & 3 & $\begin{array}{l}\text { Peripheral } \\
\text { vein }\end{array}$ & $|/| \mid$ & $\begin{array}{l}\text { Non-randomized/open } \\
\text { label }\end{array}$ \\
\hline 4 & China & Cirrhosis & N/A & N/A & N/A & N/A & N/A & $|/| \mid$ & $\begin{array}{l}\text { Non-randomized/open } \\
\text { label }\end{array}$ \\
\hline 5 & China & Cirrhosis & Allo & UC & $1.5 \times 10^{6} / \mathrm{kg}$ & $2 \sim 4$ & $\begin{array}{l}\text { Peripheral } \\
\text { vein }\end{array}$ & $\|$ & $\begin{array}{l}\text { Non-randomized/open } \\
\text { label }\end{array}$ \\
\hline 6 & China & Cirrhosis (HBV, HCV) & N/A & N/A & $1 \times 10^{6} / \mathrm{kg}$ & 4 & $\begin{array}{l}\text { Peripheral } \\
\text { vein }\end{array}$ & N/A & $\begin{array}{l}\text { Randomized/single } \\
\text { blind }\end{array}$ \\
\hline 7 & Japan & $\begin{array}{l}\text { Cirrhosis (NASH, } \\
\mathrm{HCV} \text { ) }\end{array}$ & Allo & $A D$ & N/A & 1 & $\begin{array}{l}\text { Peripheral } \\
\text { vein }\end{array}$ & $|/| \mid$ & $\begin{array}{l}\text { Non-randomized/open } \\
\text { label }\end{array}$ \\
\hline 8 & Taiwan & ACLF & Allo & $A D$ & $0.5-2 \times 10^{6} / \mathrm{kg}$ & N/A & $\begin{array}{l}\text { Peripheral } \\
\text { vein }\end{array}$ & । & $\begin{array}{l}\text { Non-randomized/open } \\
\text { label }\end{array}$ \\
\hline 9 & Singapore & Cirrhosis & Auto & BM & $0.5-1 \times 10^{6} / \mathrm{kg}$ & N/A & $\begin{array}{l}\text { Peripheral } \\
\text { vein }\end{array}$ & $|/| \mid$ & $\begin{array}{l}\text { Non-randomized/open } \\
\text { label }\end{array}$ \\
\hline 10 & China & $\begin{array}{l}\text { Alcoholic liver } \\
\text { cirrhosis }\end{array}$ & Auto & BM & $\begin{array}{l}5 \times 10^{7} \text { cells } / 10 \\
\mathrm{ml}\end{array}$ & 1 & $\begin{array}{l}\text { Hepatic } \\
\text { artery }\end{array}$ & । & $\begin{array}{l}\text { Non-randomized/open } \\
\text { label }\end{array}$ \\
\hline 11 & China & Cirrhosis (HBV) & Allo & UC & $6 \times 10^{7}(30 \mathrm{ml})$ & N/A & $\begin{array}{l}\text { Peripheral } \\
\text { vein }\end{array}$ & । & $\begin{array}{l}\text { Non-randomized/open } \\
\text { label }\end{array}$ \\
\hline 12 & China & PBC & $\mathrm{N} / \mathrm{A}$ & N/A & $0.1-1 \times 10^{6} / \mathrm{kg}$ & 3 & $\begin{array}{l}\text { Peripheral } \\
\text { vein }\end{array}$ & N/A & $\begin{array}{l}\text { Randomized/double } \\
\text { blind }\end{array}$ \\
\hline
\end{tabular}

A

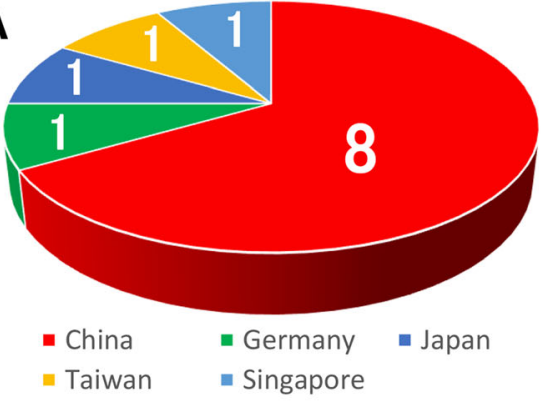

C

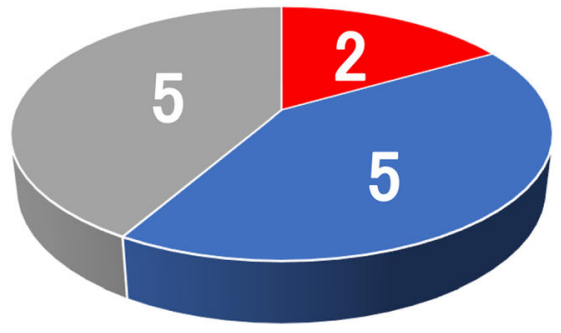

- Auto $=$ Allo $\square \mathrm{N} / \mathrm{A}$
B

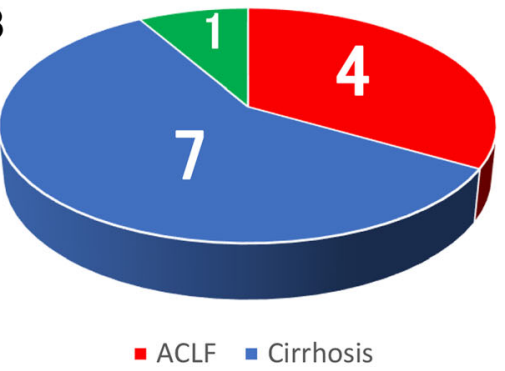

D

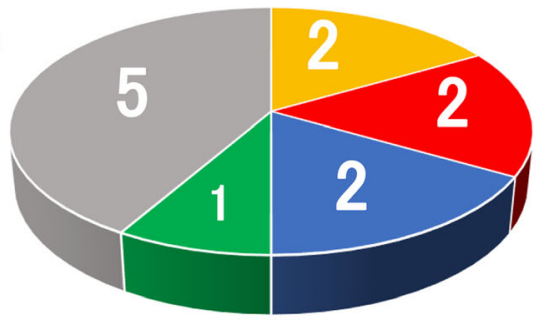

$=\mathrm{AD}=\mathrm{BM}=\mathrm{UC}=\mathrm{Skin}=\mathrm{N} / \mathrm{A}$

Fig. 2 Recent trends in clinical trials using MSCs. Proportion of country (a), disease conditions (b), autologous or allogeneic (c), and tissue origin of MSCs (d) in recent clinical trials 
reported frequencies (allogeneic, 53\%; autologous, 45\%) (Fig. 2c). Regarding the cell origin, 1 case (8.3\%) occurred in the skin, while the other cases occurred in the bone marrow ( 2 cases; $16.7 \%$ ), adipose tissue ( 2 cases; 16.7\%), and umbilical cord tissue ( 2 cases; 16.7\%). The cases of bone marrow origin were all autologous cases (Fig. 2d). The cell numbers employed in the trials slightly differed; approximately $0.1-1.0 \times 10^{6}$ cells $/ \mathrm{kg}$ were injected $1-4$ times, cell administration in 10 of the 12 cases (83.3\%) was performed via the peripheral vein, and 1 case (8.3\%) involved autologous bone marrow case from the hepatic artery, suggesting that the recent trend in administration is the peripheral vein. However, further studies of direct infusion of MSCs are necessary to achieve efficient effects. All clinical trials are still in phase I or/and II.

\section{Recent research trend of using extracellular vesicles obtained from MSCs}

Although most MSCs were trapped in the lung, they showed therapeutic effects. To explain this phenomenon, extracellular vesicles (EVs) have been evaluated [28-34]. EVs include apoptotic bodies $(50-4000 \mathrm{~nm}$ in diameter), microvesicles (MVs; $100-1000 \mathrm{~nm}$ in diameter), and exosomes (40-100 nm in diameter), among which exosomes are the most widely studied [31]. Exosomes are lipid vesicles produced by multivesicular bodies prior to extracellular secretion. They can be sedimented by ultra-centrifugation and include endosome-derived components as well as many bioactive molecules such as proteins, lipids, mRNAs, microRNAs (miRNAs), long non-coding RNAs, transfer RNA, genomic DNA, cDNA, and mitochondrial DNA [35]. Exosome membranes are enriched in cholesterol, sphingomyelin, ceramide, and lipid raft proteins. Exosomes are cell type-specific; however, they contain evolutionarily conserved sets of proteins including tetraspanins (CD81, CD63, and CD9), heat shock proteins (HSP60, HSP70, and HSP90), AlIX, and tumor susceptibility gene 101 and have been reported to have multiple functions including angiogenesis, cell proliferation, and collagen reduction. MSCs are relatively easy to expand and well-known to produce abundant exosomes and thus are theoretically ideal tools for developing cell-free therapies [28, 30-32, 34]. Haga et al. reported that mouse bone marrow-derived MSC EVs have therapeutic effects for hepatic failure induced by D-galactosamine (D-gal) and tumor necrosis factor $\alpha$. In this experiment, high levels of EVs were observed after $6 \mathrm{~h}$ in the liver and spleen. Jiang et al. reported that exosomes derived from human umbilical cord-derived MSCs alleviate acute liver failure (lipopolysaccharide/D-galactosamine-induced liver injury model) [36]. They reported that MSC exosomes reduced the activation of the NLRP3 inflammasome, IL-1 $\beta$, and IL-6 in macrophages. Borrelli et al. reported the use of drug-loaded EVs for treating hepatocellular carcinoma. Exosomes contain diverse and numerous miRNAs, and thus, determining the roles of miRNA is very difficult. Ferguson et al. reported that most previous studies used a candidate approach with specific miRNAs to assess their therapeutic effects; however, this approach may not fully capture the various biological effects induced by miRNAs in the MSC exosomes of recipient cells [29]. System-level studies are thus needed.

\section{Conclusions}

MSCs are attractive cell therapies that function as "conducting cells" against many types of immune cells and induce a variety of therapeutic effects. However, several years have passed since the first MSC theories were postulated, and thus, these clinical studies must be evaluated to determine whether MSC therapies are indeed effective in human liver diseases. In recent clinical trials, the trend of MSC therapy appears to have shifted from administration of autologous cells towards allogeneic cells. This research area is very attractive for developing effective anti-fibrotic therapies. Studies are needed to determine the most effective cell source, culture condition, cell number, administration frequency, and administration route, at low cost for treating specific liver diseases. Cell-free therapy using exosomes is an attractive approach.

\section{Abbreviations \\ ACLF: Acute on chronic liver failure; ECM: Extracellular matrix; EV: Extracellular vesicle; MSC: Mesenchymal stem cell

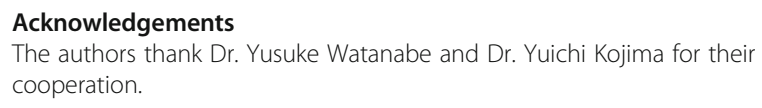 \\ Authors' contributions \\ AT, ST, TW, TY, SN, and MO analyzed and interpreted the previous literature and clinical study patient. AT and ST were the major contributors in writing the manuscript. All authors read and approved the final manuscript. \\ Funding \\ This work was supported by a Grant-in-Aid for Scientific Research (C) (18 K07903) from the Ministry of Education, Science, Technology, Sports, and Cul- ture of Japan and by the Research Program on Hepatitis from AMED to Shuji Terai (17fk0210101h0001).}

Availability of data and materials

All data generated or analyzed during this study are included in this published article.

Ethics approval and consent to participate

Not applicable.

Consent for publication

Not applicable.

\section{Competing interests}

The authors declare that they have no competing interests.

Received: 5 April 2019 Accepted: 8 August 2019

Published online: 09 September 2019

\footnotetext{
References

1. Tang LSY, Covert E, Wilson E, et al. Chronic hepatitis B infection: a review. JAMA. 2018;319:1802-13.
} 
2. Kieslich $\mathrm{K}$, Ahn J, Badano G, et al. Public participation in decision-making on the coverage of new antivirals for hepatitis C. J Health Organ Manag. 2016;30:769-85.

3. Tateishi $R$, Uchino K, Fujiwara N, et al. A nationwide survey on non-B, non-C hepatocellular carcinoma in Japan: 2011-2015 update. J Gastroenterol. 2019;54:367-76.

4. Tsuchiya A, Kojima Y, Ikarashi S, et al. Clinical trials using mesenchymal stem cells in liver diseases and inflammatory bowel diseases. Inflamm Regen. 2017;37:16.

5. Terai S, Tsuchiya A. Status of and candidates for cell therapy in liver cirrhosis: overcoming the "point of no return" in advanced liver cirrhosis. J Gastroenterol. 2017;52:129-40.

6. Angulo P, Kleiner DE, Dam-Larsen S, et al. Liver fibrosis, but no other histologic features, is associated with long-term outcomes of patients with nonalcoholic fatty liver disease. Gastroenterology. 2015;149:389-97 e10.

7. Hagstrom H, Nasr P, Ekstedt M, et al. Fibrosis stage but not NASH predicts mortality and time to development of severe liver disease in biopsy-proven NAFLD. J Hepatol. 2017;67:1265-73.

8. Sarin SK, Kumar A, Angus PW, et al. Diagnosis and management of acute variceal bleeding: Asian Pacific Association for Study of the Liver recommendations. Hepatol Int. 2011;5:607-24.

9. Olson JC, Wendon JA, Kramer DJ, et al. Intensive care of the patient with cirrhosis. Hepatology. 2011;54:1864-72.

10. Jalan R, Gines P, Olson JC, et al. Acute-on chronic liver failure. J Hepatol. 2012;57:1336-48

11. Mochida S, Nakayama N, Ido A, et al. Proposed diagnostic criteria for acuteon-chronic liver failure in Japan. Hepatol Res. 2018:48:219-24.

12. Terai $\mathrm{S}$, Ishikawa $\mathrm{T}$, Omori $\mathrm{K}$, et al. Improved liver function in patients with liver cirrhosis after autologous bone marrow cell infusion therapy. Stem Cells. 2006:24:2292-8.

13. Terai S, Sakaida I. Current status of autologous bone marrow cell infusion therapy for liver cirrhosis patients. Hepatol Res. 2008;38(Suppl 1):S72-5.

14. Watanabe $Y$, Tsuchiya A, Seino S, et al. Mesenchymal stem cells and induced bone marrow-derived macrophages synergistically improve liver fibrosis in mice. Stem Cells Transl Med. 2019;8:271-84.

15. Iwamoto T, Terai $S$, Hisanaga $T$, et al. Bone-marrow-derived cells cultured in serum-free medium reduce liver fibrosis and improve liver function in carbon-tetrachloride-treated cirrhotic mice. Cell Tissue Res. 2013;351:487-95.

16. Lee CW, Hsiao WT, Lee OK. Mesenchymal stromal cell-based therapies reduce obesity and metabolic syndromes induced by a high-fat diet. Transl Res. 2017:182:61-74 e8.

17. Chen L, Zhang C, Chen L, et al. Human menstrual blood-derived stem cells ameliorate liver fibrosis in mice by targeting hepatic stellate cells via paracrine mediators. Stem Cells Transl Med. 2017;6:272-84.

18. Kawata $Y$, Tsuchiya A, Seino $S$, et al. Early injection of human adipose tissuederived mesenchymal stem cell after inflammation ameliorates dextran sulfate sodium-induced colitis in mice through the induction of M2 macrophages and regulatory T cells. Cell Tissue Res. 2019;376(2):257-71. https://doi.org/10.1007/s00441-018-02981-w.

19. Volarevic V, Gazdic M, Simovic Markovic B, et al. Mesenchymal stem cellderived factors: immuno-modulatory effects and therapeutic potential. Biofactors. 2017;43:633-44

20. Lalu MM, McIntyre L, Pugliese C, et al. Safety of cell therapy with mesenchymal stromal cells (SafeCell): a systematic review and meta-analysis of clinical trials. PLoS One. 2012;7:e47559.

21. Forbes SJ, Newsome PN. New horizons for stem cell therapy in liver disease. J Hepatol. 2012;56:496-9.

22. Wang L, Li J, Liu H, et al. Pilot study of umbilical cord-derived mesenchymal stem cell transfusion in patients with primary biliary cirrhosis. J Gastroenterol Hepatol. 2013;28(Suppl 1):85-92.

23. An SY, Jang YJ, Lim HJ, et al. Milk fat globule-EGF factor 8 , secreted by mesenchymal stem cells, protects against liver fibrosis in mice. Gastroenterology. 2017;152:1174-86.

24. Sohni A, Verfaillie CM. Mesenchymal stem cells migration homing and tracking. Stem Cells Int. 2013;2013:130763.

25. Zhao L, Chen S, Shi X, et al. A pooled analysis of mesenchymal stem cellbased therapy for liver disease. Stem Cell Res Ther. 2018;9:72.

26. Suk KT, Yoon JH, Kim MY, et al. Transplantation with autologous bone marrow-derived mesenchymal stem cells for alcoholic cirrhosis: phase 2 trial. Hepatology. 2016;64:2185-97.

27. Lin BL, Chen JF, Qiu WH, et al. Allogeneic bone marrow-derived mesenchymal stromal cells for hepatitis B virus-related acute-on-chronic liver failure: a randomized controlled trial. Hepatology. 2017;66:209-19.
28. Jiang $\mathrm{L}$, Zhang $\mathrm{S}, \mathrm{Hu} \mathrm{H}$, et al. Exosomes derived from human umbilical cord mesenchymal stem cells alleviate acute liver failure by reducing the activity of the NLRP3 inflammasome in macrophages. Biochem Biophys Res Commun. 2019:508:735-41.

29. Ferguson SW, Wang J, Lee CJ, et al. The microRNA regulatory landscape of MSC-derived exosomes: a systems view. Sci Rep. 2018;8:1419.

30. Phinney DG, Pittenger MF. Concise review: MSC-derived exosomes for cellfree therapy. Stem Cells. 2017;35:851-8.

31. Lou G, Chen Z, Zheng M, et al. Mesenchymal stem cell-derived exosomes as a new therapeutic strategy for liver diseases. Exp Mol Med. 2017;49:e346.

32. Damania A, Jaiman D, Teotia AK, et al. Mesenchymal stromal cell-derived exosome-rich fractionated secretome confers a hepatoprotective effect in liver injury. Stem Cell Res Ther. 2018;9:31.

33. Borrelli DA, Yankson $\mathrm{K}$, Shukla N, et al. Extracellular vesicle therapeutics for liver disease. J Control Release. 2018;273:86-98.

34. Qiu G, Zheng G, Ge M, et al. Mesenchymal stem cell-derived extracellular vesicles affect disease outcomes via transfer of microRNAs. Stem Cell Res Ther. 2018;9:320

35. Cheng L, Zhang K, Wu S, et al. Focus on mesenchymal stem cell-derived exosomes: opportunities and challenges in cell-free therapy. Stem Cells Int. 2017;2017:6305295.

36. Haga $H$, Yan IK, Takahashi $K$, et al. Extracellular vesicles from bone marrowderived mesenchymal stem cells improve survival from lethal hepatic failure in mice. Stem Cells Transl Med. 2017;6:1262-72.

\section{Publisher's Note}

Springer Nature remains neutral with regard to jurisdictional claims in published maps and institutional affiliations.

Ready to submit your research? Choose BMC and benefit from:

- fast, convenient online submission

- thorough peer review by experienced researchers in your field

- rapid publication on acceptance

- support for research data, including large and complex data types

- gold Open Access which fosters wider collaboration and increased citations

- maximum visibility for your research: over $100 \mathrm{M}$ website views per year

At $\mathrm{BMC}$, research is always in progress.

Learn more biomedcentral.com/submissions 